\title{
Functional gastrointestinal disorders and smartphone use in adolescents
}

\section{To the editor,}

Functional gastrointestinal disorders (FGIDs) are common in children and they represent an important social and medical burden. ${ }^{1)}$ A recent systematic review determined that overall FGIDs prevalence in children and adolescents ranged from $9.9 \%$ to $29 \%$ and reached as high as $87 \%$ in clinical samples. ${ }^{1)}$ Several studies have investigated different risk factors, such as genetics, psychosocial characteristics, dietary habits, physical exercise, among others. ${ }^{2-4)}$ However, no studies have assessed the association between FGIDs, lifestyle habits and smartphone addiction. The present study aimed to assess the prevalence of FGIDs in children aged 11-14 years using the new Rome IV Diagnostic Criteria in a large sample and to investigate their association with lifestyle and smartphone addiction.

Our cross-sectional observational study, conducted between March and May 2019, involved students aged 11-14 years of 7 middle schools in Verona (Italy). We chose these schools because they could be representative of the different habits existing between the city, suburbs, and province. An invitation to participate to a completely anonymous questionnaires was sent to the parents of all school children. School children whose parents refused to participate were excluded from the analysis. In total, we collected 1,706 completed questionnaires.

We used a questionnaire comprising 4 parts: the first part was the Italian version of the Smartphone Addiction Scale Short Version for Adolescents and Young Adults (SAS-SV), for each item, participants expressed their opinion on a 6-point scale ranging from 1 (strongly disagree) to 6 (strongly agree). It identifies the different range for males and females. Males are addicted to scores higher than 31, with high risk of addiction with scores between 22 and 31 and females are addicted to scores higher than 33 , with high risk of addiction on scores between 22 and 33. The second part included some questions from the Harvard Youth/Adolescent Food Frequency Questionnaire. The third part investigated physical activity using some questions from the rapid assessment of physical activity questionnaire. The fourth part was the official version of the Rome Foundation questionnaire for children and adolescents to investigate FGIDs. We added a question from the Short Form 36 health survey questionnaire.

A member of our team brought the questionnaire to each class, and an explanation was provided to the school children regarding answering the questions. Questionnaires with $\geq 2$ blank or illegible answers were excluded. Continuous variables

Association between Functional Gastrolntestinal Disorders

(FGIDs) and smartphone addiction

Between 1594 italian students

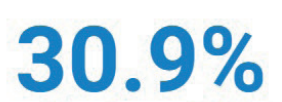

suffer from FGIDs

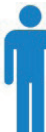

FGIDs main associations:

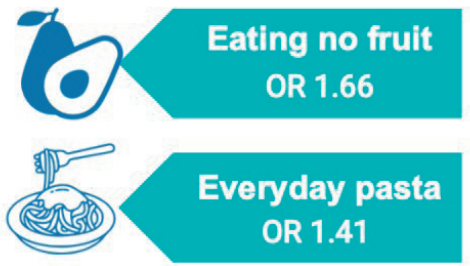

Graphical abstract

Received: 29 July, 2020, Revised: 20 October, 2020, Accepted: 24 October, 2020

This is an open-access article distributed under the terms of the Creative Commons Attribution Non-Commercial License (http://creativecommons.org/licenses/by$\mathrm{nc} / 4.0 /$ ) which permits unrestricted non-commercial use, distribution, and reproduction in any medium, provided the original work is properly cited.

Copyright ( $\odot 2021$ by The Korean Pediatric Society 
are reported as medians with interquartile ranges, and categorical variables are reported as the frequency and percentage. Chisquare tests (or Fisher exact test, where needed) were used to assess dependence between categorical variables. The logistic regression results are presented in the form of odds ratio (ORs) with $95 \%$ confidence intervals and probability values. The results were considered statistically significant when $P$ value was $\leq 0.05$.

A total of 1,594 school children were included. The mean \pm standard deviation age of the participants was $12.87 \pm 1.92$ years; $50.9 \%$ were boys ( 812 of 1,594 ), whereas $49.1 \%$ were girls (782 of 1,594), and $68.3 \%$ participants had both Italian parents $(1,089$ of 1,594$)$.

Of all participants, 30.9\% (493 of 1,594) met the Rome IV criteria for at least one FGID and 8.9\% (142 of 1,594) experienced $\geq 2$ disorders simultaneously (Table 1). FGIDs were more common in girls than in boys $(36.3 \%$ vs. $25.7 \%$, $P<0.001)$. Participants with FGIDs reported well-being less frequently compared with those who did not meet the criteria for FGIDs (29.0\% vs. 48.2\%, $P<0.001)$. Children with FGIDs reported higher requests for medical attention than other children (42.0 vs. $17.4 \%, P<0.001$; OR, $3.44 ; 95 \%$ confidence interval $[\mathrm{CI}], 2.72-4.34 ; P<0.001)$.

Having breakfast is the most significative dietary factor among those we have studied, because it is associated with FGIDs in students who never had it or had it less than once a week (OR, 1.50 ; 95\% CI, 1.09-2.05; $P=0.011$ ), instead, students who had breakfast every day present lower prevalence of FGIDs (OR, 0.73 ; 95\% CI, 0.57-0.90; $P=0.004)$. The participants who performed only some light activities during the week had 1.47 times higher odds of experiencing FGIDs (95\% CI, 1.06-2.03; $P=0.02$ ).

Based on the SAS-SV questionnaire, 22.4\% participants were addicted $(358$ of 1,594$)$ to smartphones. Participants with FGIDs demonstrated a higher prevalence of smartphone addiction than those who did not meet the criteria for FGIDs $(29.6 \%$ vs. $19.3 \%, P<0.001$ ) (Fig. 1). Children with smartphone addiction exhibited a 1.98 times higher chance of having FGIDs (95\% CI, 1.47-2.68; $P<0.001)$. Participants who reported the feeling of well-being had a lower prevalence of smartphone addiction than other participants ( $18.0 \%$ vs. $25.8 \%, P<0.001)$.

The fitted multiple logistic regression model showed that the nonconsumption of fruit (OR, 1.66; 95\% CI, 1.17-2.36; $P=0.005)$, consumption of pasta every day (OR, $1.41 ; 95 \% \mathrm{CI}$, $1.12-1.77 ; P=0.003)$, female sex (OR, 1.64; 95\% CI, 1.31$2.05 ; P<0.001)$, and smartphone addiction $(\mathrm{OR}, 2.02 ; 95 \% \mathrm{CI}$, $1.49-2.76 ; P<0.001)$ are associated with the presence of FGIDs.

The first important result was the high prevalence of pediatric FGIDs in our population as determined according to the Rome IV criteria. Studies with prevalence of $>30.0 \%$ have not been previously published; our sample reported a prevalence of $30.9 \%$. Our results should be considered by pediatricians in their daily clinical practice as well as for public health in general because FGIDs can influence the psychosocial life of people affected and they could affect the quality of life of children. $\left.{ }^{5}\right)$ The difference in prevalence among the 3 studies we have shown in Table 1 should be linked to many factors. In particular, it is important to take into account the difference in weather, diet (different diets have different levels of FODMAP [fermentable, oligo-, di-, mono-saccharides and polyol]) and social economic level (that influence the life style) between the 3 different countries. ${ }^{6-8)}$

FGIDs are associated with several risk factors. In fact, dietary habits can influence the onset of these disorders, also physical activity is correlated with these disorders. These findings have public health relevance with regard to the global increase in consumption of unhealthy foods and sedentary behavior. Therefore, initiatives aimed at promoting healthier lifestyles

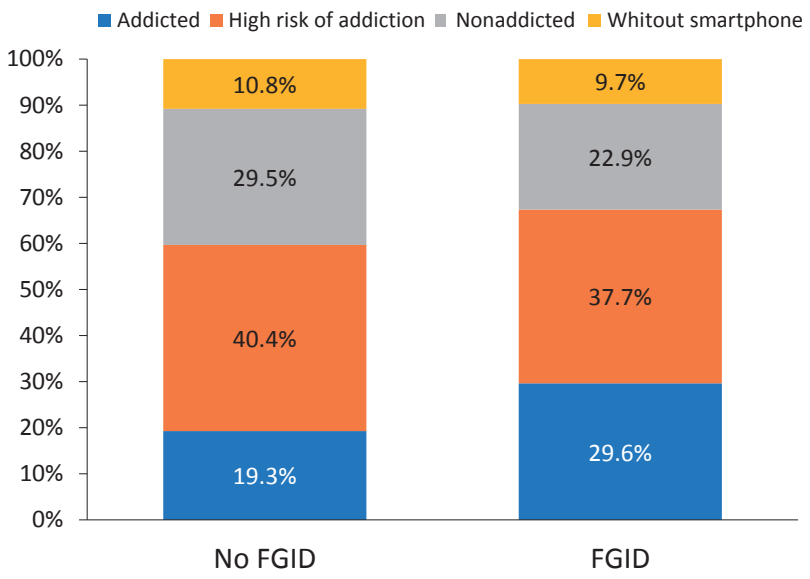

Fig. 1. Distribution of smartphone use according to functional gastrointestinal disorder (FGID) status.

Table 1. Comparison of FGID prevalence reported among studies using Rome IV criteria

\begin{tabular}{|c|c|c|c|c|c|c|c|c|c|c|c|c|c|c|}
\hline \multirow[b]{2}{*}{ Study } & \multirow[b]{2}{*}{ Sample } & \multirow[b]{2}{*}{ Country } & \multirow[b]{2}{*}{$\begin{array}{l}\text { Prevalence } \\
\text { of FGIDs }\end{array}$} & \multicolumn{5}{|c|}{ Functional nausea and vomiting disorders } & \multicolumn{4}{|c|}{ Functional abdominal pain disorders } & \multicolumn{2}{|c|}{$\begin{array}{l}\text { Functional defecation } \\
\text { disorders }\end{array}$} \\
\hline & & & & $\begin{array}{c}\text { Cyclic } \\
\text { vomiting } \\
\text { syndrome }\end{array}$ & $\begin{array}{l}\text { Func- } \\
\text { tional } \\
\text { nausea }\end{array}$ & $\begin{array}{l}\text { Func- } \\
\text { tional } \\
\text { vomiting }\end{array}$ & $\begin{array}{l}\text { Adolescent } \\
\text { rumination } \\
\text { syndrome }\end{array}$ & $\begin{array}{l}\text { Aero- } \\
\text { phagia }\end{array}$ & $\begin{array}{l}\text { Functional } \\
\text { dyspepsia }\end{array}$ & IBS & $\begin{array}{l}\text { Abdominal } \\
\text { migraine }\end{array}$ & $\begin{array}{l}\text { Functional } \\
\text { abdominal } \\
\text { pain-NOS }\end{array}$ & $\begin{array}{l}\text { Functional } \\
\text { constipa- } \\
\text { tion }\end{array}$ & $\begin{array}{l}\text { Nonretentive } \\
\text { fecal } \\
\text { incontinence }\end{array}$ \\
\hline $\begin{array}{l}\text { Saps et al., } \\
2018\end{array}$ & 3,567 & Colombia & $755(21.2)$ & $16(0.5)$ & $3(0.1)$ & $22(0.6)$ & $16(0.5)$ & $19(0.5)$ & $108(3.0)$ & $83(2.3)$ & $18(0.5)$ & $85(2.4)$ & $382(10.7)$ & $3(0.1)$ \\
\hline $\begin{array}{l}\text { Robin et al., } \\
2018\end{array}$ & 59 & USA & $240(25.0)$ & $19(2.0)$ & $5(0.5)$ & $13(1.4)$ & $0(0)$ & $25(2.6)$ & $73(7.6)$ & $49(5.1)$ & $11(1.1)$ & $30(3.1)$ & $135(14.1)$ & $2(0.2)$ \\
\hline $\begin{array}{l}\text { Our study, } \\
2019\end{array}$ & 1,594 & Italy & $493(30.9)$ & $64(4.0)$ & $31(1.9)$ & $15(0.9)$ & $13(0.8)$ & $15(0.9)$ & $150(9.4)$ & $71(4.5)$ & $51(3.2)$ & $9(0.6)$ & $280(17.6)$ & $4(0.26)$ \\
\hline
\end{tabular}

FGID, functional gastrointestinal disorder; IBS, irritable bowel syndrome; NOS, not otherwise specified. 
among students should be encouraged and planned.

Finally, the most significant element of our investigation is the association between smartphone use and FGIDs prevalence. A new data, never investigated in the literature, were the association between FGIDs and smartphone addiction. As the number of smartphone users increases, problems related to smartphone use also become more serious. This phenomenon can have negative consequences on a psychological and social level and could result in health issues.

A limitation of the study is the use of questionnaires: in fact, the information provided by individual students may be inaccurate. Another possible limitation is that the survey by questionnaire does not consider any organic disturbance underlying the reported gastrointestinal symptoms. If casual relationships are present within the population, then this type of study cannot provide any information about that relationship.

\section{Key message}

Question: Are functional gastrointestinal disorders (FGIDs) common in Italy? If so, what are the associated risk factors?

Finding: In this cross-sectional study of 1,594 adolescents, the prevalence of FGIDs was $30.9 \%$ and was mainly associated with smartphone addiction.

Meaning: Smartphone use and dietary habits should be monitored in children with FGIDs.

Mauro Cinquetti, $\mathrm{MD}^{1}$, Marco Biasin, $\mathrm{MD}^{2}$, Marco Ventimiglia, $\mathrm{MSc}^{3}$, Linda Balanzoni, $\mathrm{MD}^{1}$, Denise Signorelli, $\mathrm{MD}^{4}$, Angelo Pietrobelli, $\mathrm{MD}^{2,5}$

${ }^{1}$ Maternal and Child Department, U.O.S. Ricerca Clinica e Valutazione Farmaci e Nucleo per la Ricerca Clinica (N.R.C.), Verona, Italy

${ }^{2}$ Department of Surgical Sciences, Dentistry, Gynecology and Pediatrics, University of Verona, Verona, Italy

${ }^{3}$ IBD Unit, Villa-Sofia Hospital, Palermo, Italy ${ }^{4}$ Health Management, Azienda ULSS 9 Scaligera, Verona, Italy ${ }^{5}$ Pennington Biomedical Research Center, Baton Rouge, LA, USA

Corresponding author: Mauro Cinquetti, MD

Maternal and Child Department - U.O.S. Ricerca Clinica e Valutazione Farmaci e Nucleo per la Ricerca Clinica (N.R.C.), via Circonvallazione 1, San Bonifacio (Verona) ZIP code 37047 , Italy

\Email: dott.maurocinquetti@gmail.com

https://orcid.org/0000-0002-3641-5350

\section{Footnotes}

Ethics statement: This study was approved by the U.O.S. Ricerca Clinica Valutazionione Farmaci Nucleoper la Ricerca Clinica (N.R.C.) of Azienda ULSS 9 Skaligera.

Conflicts of interest: No potential conflict of interest relevant to this article was reported.

ORCID:

Mauro Cinquetti @ https://orcid.org/0000-0002-3641-5350

Marco Biasin @ https://orcid.org/0000-0002-4087-4840

\section{References}

1. Boronat AC, Ferreira-Maia AP, Matijasevich A, Wang YP. Epidemiology of functional gastrointestinal disorders in children and adolescents: a systematic review. World J Gastroenterol 2017;23:3915-27.

2. Xu JR, Shang L, Si WL, Song Y, Wang Y, Ma JL, et al. A population-based study of associations between functional gastrointestinal disorders and psychosocial characteristics in Xi'an, China. Neurogastroenterol Motil 2013;25:617-e467.

3. Shau JP, Chen PH, Chan CF, Hsu YC, Wu TC, James FE, et al. Fast foods-are they a risk factor for functional gastrointestinal disorders? Asia Pac J Clin Nutr 2016;25:393-401.

4. Strid H, Simrén M, Störsrud S, Stotzer PO, Sadik R. Effect of heavy exercise on gastrointestinal transit in endurance athletes. Scand $\mathrm{J}$ Gastroenterol 2011;46:673-7.

5. Varni JW, Bendo CB, Nurko S, Shulman RJ, Self MM, Franciosi JP, et al. Health-related quality of life in pediatric patients with functional and organic gastrointestinal diseases. J Pediatr 2015;166:85-90.

6. Saps M, Hudgens S, Mody R, Lasch K, Harikrishnan V, Baum C. Seasonal patterns of abdominal pain consultations among adults and children. $\mathrm{J}$ Pediatr Gastroenterol Nutr 2013;56:290-6.

7. Marsh A, Eslick EM, Eslick GD. Does a diet low in FODMAPs reduce symptoms associated with functional gastrointestinal disorders? A comprehensive systematic review and meta-analysis. Eur J Nutr 2016;55: 897-906.

8. Hongo M. Epidemiology of FGID symptoms in Japanese general population with reference to life style. J Gastroenterol Hepatol 2011;26 Suppl 3:19-22.

9. Saps M, Velasco-Benitez CA, Langshaw AH, Ramírez-Hernández CR. Prevalence of functional gastrointestinal disorders in children and adolescents: comparison between Rome III and Rome IV Criteria. J Pediatr 2018;199:212-6.

10. Robin SG, Keller C, Zwiener R, Hyman PE, Nurko S, Saps M, et al. Prevalence of pediatric functional gastrointestinal disorders utilizing the Rome IV Criteria. J Pediatr 2018;195:134-9.

How to cite this article: Cinquetti M, Biasin M, Ventimiglia M, Balanzoni L, Signorelli D, Pietrobelli A. Functional gastrointestinal disorders and smartphone use in adolescents. Clin Exp Pediatr 2021;64:494-6. https://doi.org/10.3345/cep.2020.01326 